\title{
Comparing and Identifying Influential Factors of Technological Innovation Efficiency in Manufacturing and Service Industries Using DEA: A Study of SMEs in South Korea
}

\author{
Chae Hyun Im ${ }^{1}$ and Keun Tae Cho ${ }^{1,2, *}$ \\ 1 Graduate School of Management of Technology, Sungkyunkwan University, Seoburo 2066, \\ Suwon 16419, Korea; limch@skku.edu \\ 2 Department of Systems Management Engineering, Sungkyunkwan University, Seoburo 2066, \\ Suwon 16419, Korea \\ * Correspondence: ktcho@skku.edu; Tel.: +82-031-290-7602
}

Citation: Im, C.H.; Cho, K.T. Comparing and Identifying Influential Factors of Technological Innovation Efficiency in

Manufacturing and Service Industries Using DEA: A Study of SMEs in South Korea. Sustainability 2021, 13, 12945. https://doi.org/10.3390/ su132312945

Academic Editors: Daryl Powell, David Romero, Paolo Gaiardelli and Antonella Petrillo

Received: 16 September 2021 Accepted: 19 November 2021 Published: 23 November 2021

Publisher's Note: MDPI stays neutral with regard to jurisdictional claims in published maps and institutional affiliations.

Copyright: (c) 2021 by the authors. Licensee MDPI, Basel, Switzerland. This article is an open access article distributed under the terms and conditions of the Creative Commons Attribution (CC BY) license (https:// creativecommons.org/licenses/by/ $4.0 /)$.

\begin{abstract}
Although technological innovation is critical for growth and future survival, small and medium scale enterprises (SMEs) are at a disadvantage compared to larger organizations given the resources available. It is important to examine the possible methods for making research and development more efficient. This study analyzes the technological innovation efficiency of SMEs in the manufacturing and service industries in South Korea and determines the factors affecting efficiency. The models of data envelopment analysis and Tobit regression analysis were used. According to the analysis results, the technical and pure technical efficiencies were higher in the service industry than in the manufacturing industry. The factors affecting efficiency were also different between the two industries. This study is significant because it evaluates the innovation activity efficiency of small and medium manufacturing and service companies in South Korea and provides specific criteria and a rationale to improve the efficiency.
\end{abstract}

Keywords: data envelopment analysis; DEA; small and medium-sized enterprises; technological innovation; efficiency

\section{Introduction}

Innovation refers to new or dramatically improved products or processes of institutional units, including companies, that, when implemented, affect operational performance such as revenue, cost, and quality [1]. Research and development (R\&D) activity-based technological innovations are increasingly emphasized for companies in the Fourth Industrial Revolution [2-4]. In the second and third industrial revolutions, the success or failure of companies depended on who created and supplied products or services, cheaper and faster, using capital and physical competitiveness. However, in the market environment of the hyper-connectivity-based fourth industrial revolution era, customers respond to companies that can reflect the needs of individuals while supplying dramatically improved innovative products or services promptly [5]. Such products and services allow companies to gain a competitive advantage in the market, and success in the market further accelerates the company's technological innovation. In a company's business activities, technological innovation is no longer a strategic option, but rather an essential factor that determines the success or failure of a company [6].

Previously, a company's primary goal was to achieve a competitive advantage in technological innovation, as it was the source of growth. However, the concept of innovation efficiency - with which larger outputs are produced with smaller inputs in managing technological innovation activities-has also drawn attention. Efficiency is a relative concept used for benchmarking or providing corporate strategic implications because it can provide a baseline for a comparative evaluation of technological innovation levels $[7,8]$. 
When new growth engines are required in the fourth industrial revolution era, the technological innovation of small and medium-sized enterprises (SMEs) may be a determinant of survival and sustainable growth in the industrial and national dimensions $[9,10]$. However, the technological innovation speed of SMEs preparing for the future is insufficient compared to that of large enterprises due to limitations in technology, professional manpower, and infrastructure [11]. Therefore, it is necessary to find various measures to increase the efficiency of technological innovation using limited resources to secure the competitiveness of SMEs in the Fourth Industrial Revolution era [12]. SMEs in South Korea refer to companies with total assets of less than 500 billion won that meet all the external and independence criteria stipulated in the Basic Law for SMEs [13]. In South Korea, SMEs accounted for $99.9 \%$ (6.52 million) of the total companies as of the end of 2017 and are a significant axis of the country's economy and industries, in which $82.9 \%$ (15.99 million) of total workers are employed [14].

Existing research on technological innovation has mostly been conducted for statistical significance through regression analysis for workforce or financial indicators using indirect corporate data as well as to conduct fact-finding surveys, such as customer satisfaction, using questionnaires. [15]. This study aims to analyze the relative operational efficiency of SMEs by using the manpower and cost information that directly contributed to technological innovation, going beyond the existing research methods. It additionally suggests plans for efficiency improvement.

Furthermore, this study comparatively analyzed the efficiency of SMEs' technological innovation activities, focusing on the manufacturing and service industries. These industries accounted for $24.9 \%$ and $57.0 \%$ of the gross domestic product (GDP) of South Korea in 2020, respectively [16]. The strategy of innovation activities depends on an industry's technical opportunities and knowledge cumulativeness, appropriateness, and knowledge base. In particular, there are considerable differences in innovation patterns between the manufacturing and service industries [17-19]. The manufacturing industry is characterized by producing tangible outputs, having little customer contact, and being capital-intensive. Conversely, the service industry is characterized by producing intangible outputs, excessive direct customer contact, and is labor intensive [20]. Consequently, in this study, the industrial factors affecting technological innovation efficiency were examined through integrated and individual analyses of the two industries, which show different innovation patterns and industrial characteristics.

Furthermore, in this study, a linear programming-based data envelopment analysis (DEA) method was used for efficiency analysis. DEA is an effective method for evaluating performance because it measures the relative efficiency against the most efficient entity by simultaneously considering multiple input and output variables [21]. DEA can analyze the measured values in different units without applying arbitrary weights to the variables measured. Moreover, as its measurement models do not assume certain functional forms, they facilitate efficiency analyses using various variables that affect the technological innovation performance of SMEs. Thus, its usefulness has been widely verified [22-29].

This study is unique because the DEA analysis is used with the Tobit regression analysis (used when the dependent variable is detected as a value within a specific range) to assess the technological innovation influencing factors by industry group.

If standard indicators of efficient technological innovation companies are derived through an approach using DEA and the Tobit model and used as a benchmark case, it is thought that it will contribute to the improvement of the technological innovation efficiency of small and medium-sized enterprises. In addition, if we can confirm, through this study, the general innovation pattern that appears according to industry, it is expected that it will be useful not only for corporate activities but also for national policy establishment.

The remainder of this paper is organized as follows. Following the introduction in Section 1, Section 2 examines the definitions of the DEA model, the Wilcoxon-MannWhitney test, and the Tobit regression model, and examines prior studies related to Korean technological innovation research and DEA research for SMEs. Section 3 establishes the 
hypotheses and identifies the variables and research models. In Section 4, descriptive statistical analysis of variables and efficiency evaluation through DEA are presented. This section also discusses the identifying factors and differences affecting the efficiency based on the average value of the efficiency of the manufacturing and service industries classified into high-and low-efficiency groups. Finally, in Section 5, the main research results and implications of this study are drawn, and future research directions are derived based on the limitations of this study.

\section{Literature Review}

\subsection{DEA Model}

DEA is a method that applies a linear programming model to the inputs and outputs to select the best decision-making units (DMUs) and derives the optimal values from the best DMUs to measure relative efficiency. When the relative efficiency is 100\% in DEA, it means that the outputs cannot be increased any further unless the input variables increase or other parts of the outputs decrease compared to the most efficient DMU [30].

DEA can compare multiple input and output variables to measure the relative efficiency of DMUs. It can also apply other analysis units, such as continuous, ordinal, and nominal variables, for data selection [31]. The efficiency measurement results of DEA are affected by the number of DMUs and the input and output variables. Therefore, if the number of DMUs increases, the discriminating power of the DEA model increases; if the number of variables increases, the discriminating power decreases. Nevertheless, DEA can help improve actual efficiency because it can determine the efficiency value by considering various input variables simultaneously based on the DMUs and provide numerical information regarding the sections and its scale where the inefficiency occurs [32].

Several DEA models have been proposed to better reflect the efficiency. These include the Charnes, Cooper, and Rhodes (CCR) model, which assumes a constant return to scale (CRS) in the input aspect proposed by Charnes, et al. [33]; the Banker, Charnes, and Cooper (BBC) model, which assumes a variable return to scale [34]; and the Byrnes, Fare, and Grosskopf (BFG) model [35], which assumes a non-increasing return to scale (NRS). Among them, the CCR and BCC models are most frequently used in DEA [36-38].

The CCR model assumes that CRS, in which the output variables increase as the scale increases, is the most basic DEA model. In the CCR model, the ratio of output variables to input variables must not exceed 1 . The weights that maximize the inputs and outputs are determined under the condition that the weight of each input and output variable is larger than 0 . However, the CCR model cannot reflect various constraints, such as imperfect competition, and cannot distinguish between scale efficiency (SE) and pure technical efficiency (PTE).

As a supplement to the CCR model, the BCC model was developed by Banker, Charnes and Cooper [34] to reflect SE by mitigating the CRS assumption of the CCR model. The BCC model can distinguish between the SE and PTE. In the SE model, the value of the overall technical efficiency calculated by the CCR model is divided by the value of the PTE calculated by the BCC model. Consequently, the value approaches 1 , and the scale is closer to the optimal value. Therefore, if the SE value is 1 , the optimal scale state is achieved; if the $\mathrm{SE}$ value is less than 1 , there is inefficiency in the scale.

CCR efficiency is called technical efficiency (TE), and as BCC efficiency assumes VRS, it is called PTE. If the CCR and BCC models are compared, the relationship of CCR $\leq$ BCC holds. Therefore, observation values not included in the optimal values of the CCR model can be included in the optimal values of the BCC model, implying that the number of observation values evaluated as efficient in the BCC model may be greater than that of the CCR model.

\subsection{Wilcoxon-Mann-Whitney Test}

The Wilcoxon-Mann-Whitney test, a non-parametric test, was used to examine the efficiency difference between the groups. DEA uses ordinal variables or categories for the 
measurements. Thus, if a common continuous variable validation, such as a t-test, is used in the comparison stage of efficiency between the groups in this study, the largest classification category will be represented as an open-end category with a value larger than a certain pre-set value. Hence, the t-test result will become significantly different [39,40], implying that it is inappropriate to apply continuous variable validation. Thus, it is appropriate to use a non-parametric test such as the Wilcoxon-Mann-Whitney test, based on rank order without distinguishing the values of categories.

\subsection{Tobit Regression Model}

In DEA, the efficiency value is within a limited range of values between 0 and 1 . Therefore, its distribution has certain limitations. As it is different from ordinary, normal distributions, an error that underestimates the effect of the variable may occur if ordinary least squares (OLS) is applied [41]. This study applied a Tobit regression model to analyze the cause of efficiency to avoid such errors. The problem is solved by setting the efficiency index as a dependent variable and the factors affecting efficiency as independent variables. This will identify the size of the effect while simultaneously applying a regular regression model.

On the other hand, the inability to consider factors other than the independent variables that were subjectively selected and examined in this study can be a limitation of the Tobit model.

\subsection{Previous Studies on Innovation and Technology Development of Korean SMES}

Previous research on technological innovation and the development of Korean SMEs has focused on corporate performance, government-supported projects and policies, and the effects of external cooperation. Regarding corporate performance, Park and Lee [42] analyzed the impact of innovation activities on the performance of small-and mediumsized manufacturers. They found that R\&D performance, such as patent applications and sales, are important indicators of innovation capabilities and activities. Kang and Park [43] examined the relationship between innovation performance and capabilities and confirmed that different types of technological innovation capabilities contribute uniquely to each growth stage of the company.

Bae [44] analyzed how participation in R\&D projects affects the employment rate changes of companies that participate in government technological innovation development projects targeting SMEs. The analysis shows that the scale of government investment significantly impacts employment growth, especially in large-scale R\&D groups. Sohn, et al. [45] analyzed the impact of government regulation on SMEs' technological innovation achievements through logistic and negative binomial regression analyses. They found that appropriate regulation could have a positive effect in reducing the market failure of enterprises and increasing technological innovation performance.

Park, et al. [46] analyzed the results of R\&D conducted in collaboration with government research institutes using a logistic model to investigate the effects of external cooperation on the technological innovation of information and communication technology (ICT) SMEs. Consequently, it was confirmed that cooperation between industry and government research institutes was effective for SMEs' technological innovation. Additionally, Kang [47] conducted an empirical analysis to understand the impact of external cooperation on the innovation performance of local SMEs. The analysis confirmed that there is a significant positive correlation between the joint R\&D and innovation performance of SMEs, and that the cooperative activities of enterprises with excellent technological capabilities have a greater impact on innovation performance.

\subsection{Previous Studies on SME and Technological Innovation Efficiency Analysis Using DEA}

Table 1 shows that DEA has been used to conduct an efficiency analysis of SMEs in various studies. These studies can be divided into financial performance, management and operation strategies, R\&D, and technological activities. 
Table 1. Previous studies that analyzed efficiency using DEA for SMEs.

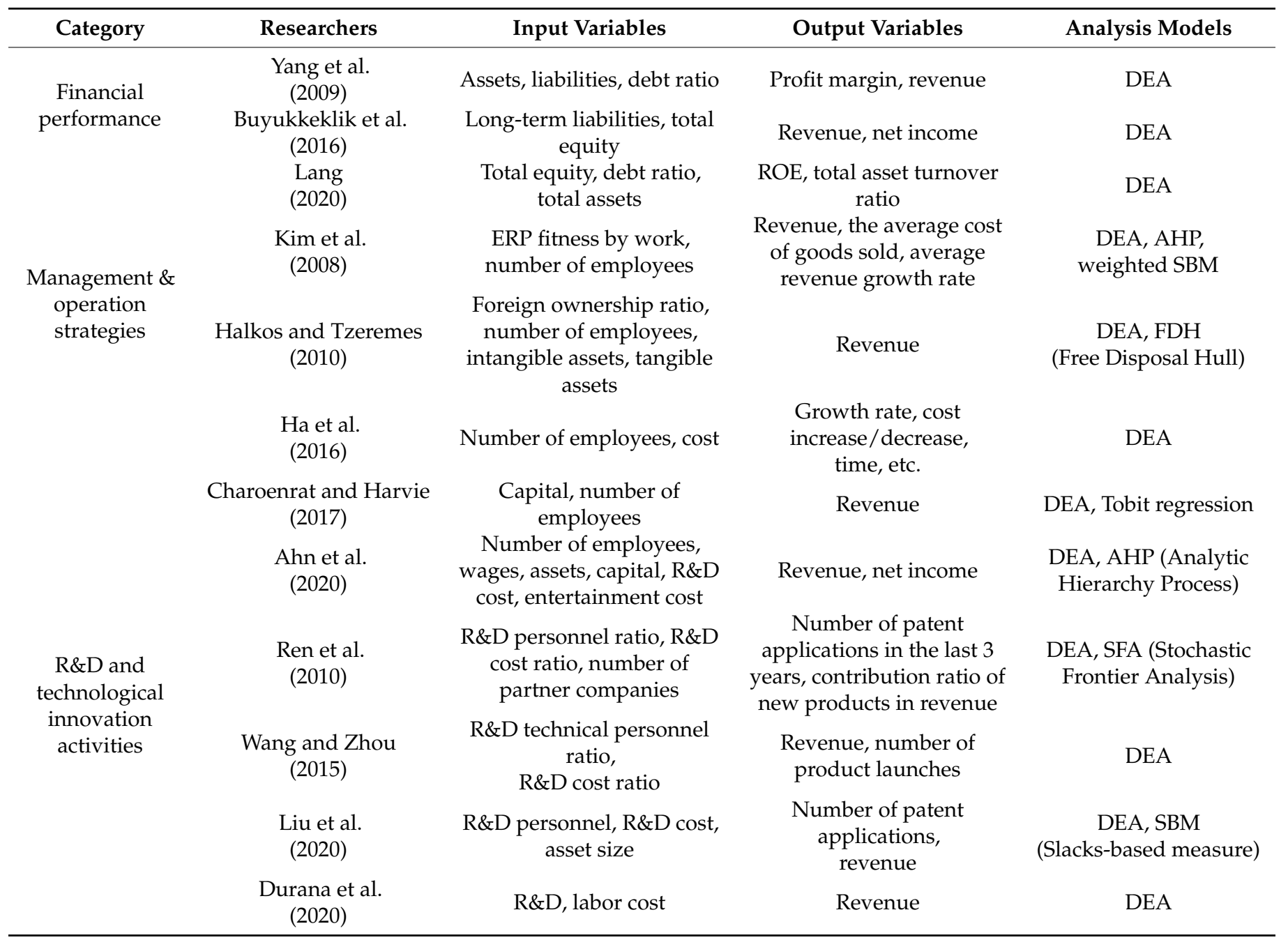

First, some studies set corporate financial indicators as input and output variables to perform an overall business management assessment of a company. Yang, et al. [48], in a study on the capital financing efficiency of high-tech SMEs in Beijing, China, used the assets, liabilities, capital, and debt ratio as input variables and profit margin, and revenue as output variables. They found that, as the size of SMEs decreases, capital financing efficiency declines and the financial leverage effect decreases [48]. While Buyukkeklik, et al. [49] used long-term liabilities and total equity as input variables to investigate the financial capital utilization efficiency of SMEs in Turkey and revenue and net income as output variables. They confirmed that, as financial status deteriorates, the efficient use of financial capital becomes increasingly difficult [49]. Furthermore, to analyze the capital financing efficiency of SMEs in Chinese countries, Lang [50] used the newly increased total financial equity, debt ratio, and total assets in 2018 and 2019 as input variables for 706 Chinese high-tech SMEs together with return on equity (ROE) and total asset turnover ratio as output variables. Lang [50] demonstrated that inefficiency was caused by SE and suggested that financial support reviews and measures should be tailored to company size for high-tech SMEs.

Second, studies have been conducted on the efficiency of management and operational strategies. These studies include those of Kim, et al. [51], Halkos and Tzeremes [52], Ha, et al. [53], Charoenrat and Harvie [54], and Ahn, et al. [55]. Kim, Yoo and Song [51] created ERP operation efficiency indicators for South Korean SMEs in automotive parts and examined the operational efficiency of enterprise resource planning (ERP) system implementation; they suggested the ideal inputs/outputs of companies. Halkos and 
Tzeremes [52] performed DEA, based on the management efficiency evaluation of foreign SMEs operating in Greece, to investigate the effect of foreign ownership on companies. The results empirically reveal that high foreign ownership has a positive effect on SME efficiency. Ha, Lee and Kim [53] analyzed the servitization efficiency of South Korean's small and medium manufacturers using DEA by dividing companies into four types of management strategies. The results confirmed that the customized strategies were more efficient than the strategies for providing standard products/services, and that business management support activities had a positive effect on efficiency. Charoenrat and Harvie [54] investigated the changes in the management efficiency of small and mediumsized manufacturers in Thailand using data on 22,685 SMEs registered in the National Statistical Office of Thailand in 1997 and 56,441 SMEs registered in 2007. They identified eight important factors (company size, company age, number of skilled employees, location, corporate ownership type, cooperatives, foreign investment size, and export size) that determine the management efficiency of Thai manufacturing SMEs [54]. Additionally, Ahn, Kim, Park and Kim [55] proposed criteria for the excellent efficiency of SMEs that manufacture broadcasting and wireless communication equipment and presented strategic information to increase the efficiency of low-efficiency companies.

Third, some studies have used DEA to analyze the efficiency of the R\&D or technological activities of SMEs. Ren, Zhang and Yi [27] selected 80 SMEs to perform an empirical analysis of the technological innovation efficiency of SMEs in Guangdong Province, China, and proposed efficiency improvement measures in the Guangdong region, comparing their efficiencies. Further, to examine the technological innovation efficiency of SMEs in the Xi'an High-tech Zone, China, by industrial sector and year, Wang and Zhou [28] used R\&D performance data of five high-tech industrial sectors between 1999 and 2004 as input and output variables. Moreover, Liu, Hou, Zhan and Wang [25] evaluated the efficiency of technological innovation activities of high-tech material manufacturing SMEs listed in China between 2012 and 2015 and empirically analyzed the factors for improvements. Durana, Zauskova, Vagner and Zadnanova [22] classified 132 Slovak small-and medium-sized manufacturers into eight industrial groups. They evaluated the efficiency of technological innovation activities for each group by setting R\&D and labor costs as input variables and revenue as output variables.

In addition to investigating the topics used in previous studies on the efficiency of SMEs (Table 2), the composition and frequency of the variables were investigated to determine which input and output variables were used on innovation activities using DEA $[8,22,25,27,28,56-61]$. The studies on technological innovation activities used 11 input variables, including company size, number of full-time employees, percentage of master's degree holders, R\&D labor cost, R\&D personnel ratio, R\&D headcount, innovation and $R \& D$ costs, and innovation and R\&D ratio. Among them, the "innovation and R\&D costs" variable was adopted in nine studies, followed by the "R\&D headcount", "asset size", and "R\&D labor cost variables" in three studies each.

The output variables included revenue contribution ratio, revenue, patent registration rate, number of patent citations, number of patent claims, and patent applications. This implies that indicators related to revenue and patents are mainly used as output variables for innovation and R\&D evaluations. In particular, seven out of 11 papers adopted the "number of patent applications" variable-the highest frequency; "revenue" and "number of product launches" were chosen four times, showing the second highest frequency.

Furthermore, other variables were only used for innovation and R\&D ratio; training cost, percentage of master's degree holders, and number of partner companies as input variables; and revenue growth rate, $\mathrm{ROE}$, equity growth rate, patent registration rate, number of patent citations, number of patent claims, and number of innovative companies as output variables. In sum, various variables were used in the studies reflecting the characteristics of DEA, in which two or more relevant items can be selected as input/output variables. 
Table 2. Summary of input and output variables of research related to innovation and R\&D.

\begin{tabular}{|c|c|c|c|c|c|c|c|c|c|c|c|c|c|}
\hline \multirow[t]{2}{*}{ Type } & \multirow[t]{2}{*}{ Previous Studies } & \multirow{2}{*}{$\begin{array}{l}\text { Choi } \\
\text { et al. }\end{array}$} & \multirow{2}{*}{$\begin{array}{l}\begin{array}{c}\text { Ren } \\
\text { et al. }\end{array} \\
(2010)\end{array}$} & \multirow{2}{*}{$\begin{array}{l}\text { Suh } \\
\text { and } \\
\text { Kim } \\
(2011)\end{array}$} & \multirow{2}{*}{$\begin{array}{l}\begin{array}{l}\text { Kim } \\
\text { et al. }\end{array} \\
(2012)\end{array}$} & \multirow{2}{*}{$\begin{array}{c}\text { Wang } \\
\text { and } \\
\text { Zhou }\end{array}$} & \multirow{2}{*}{$\begin{array}{c}\begin{array}{c}\text { Lee } \\
\text { et al. }\end{array} \\
(2016)\end{array}$} & \multirow{2}{*}{$\begin{array}{c}\text { Kim } \\
\text { (2016) }\end{array}$} & \multirow{2}{*}{$\begin{array}{l}\text { Park } \\
\text { et al. }\end{array}$} & \multirow{2}{*}{$\begin{array}{c}\begin{array}{c}\text { Liu } \\
\text { et al. }\end{array} \\
(2020)\end{array}$} & \multirow{2}{*}{$\begin{array}{c}\begin{array}{c}\text { Durana } \\
\text { et al. }\end{array} \\
(2020)\end{array}$} & \multirow{2}{*}{$\begin{array}{l}\text { Guede } \\
\text {-Cid } \\
\text { et al. } \\
(2021)\end{array}$} & \multirow[t]{2}{*}{ Tota } \\
\hline & & & & & & & & & & & & & \\
\hline \multirow{10}{*}{ Input } & Innovation and R\&D costs & $\mathrm{O}$ & & $\mathrm{O}$ & $\mathrm{O}$ & $\mathrm{O}$ & $\mathrm{O}$ & $\mathrm{O}$ & $\mathrm{O}$ & $\mathrm{O}$ & $\mathrm{O}$ & & 9 \\
\hline & R\&D headcount & & & $\mathrm{O}$ & & & $\mathrm{O}$ & & & $\mathrm{O}$ & & $\mathrm{O}$ & 3 \\
\hline & Asset size & & & & & & & & $\mathrm{O}$ & $\mathrm{O}$ & & $\mathrm{O}$ & 3 \\
\hline & R\&D labor cost & & & & & & & & $\mathrm{O}$ & & $\mathrm{O}$ & & 2 \\
\hline & R\&D personnel ratio & & $\mathrm{O}$ & & & $\mathrm{O}$ & & & & & & & 2 \\
\hline & Company size & & & & $\mathrm{O}$ & & & $\mathrm{O}$ & & & & & 2 \\
\hline & Full-time employees & $\mathrm{O}$ & & & $\mathrm{O}$ & & & & & & & & 2 \\
\hline & Innovation and $R \& D$ cost ratio & & $\mathrm{O}$ & & & & & & & & & & 1 \\
\hline & Training cost & & & & & & & & & & & $\mathrm{O}$ & 1 \\
\hline & Master degree percentage & $\mathrm{O}$ & & & & & & & & & & & 1 \\
\hline \multirow{11}{*}{ Output } & No. of partner companies & & $\mathrm{O}$ & & & & & & & & & & 1 \\
\hline & No. of patent applications & $\mathrm{O}$ & $\mathrm{O}$ & $\mathrm{O}$ & $\mathrm{O}$ & & $\mathrm{O}$ & $\mathrm{O}$ & & $\mathrm{O}$ & & & 7 \\
\hline & Revenue & & & & & $\mathrm{O}$ & & & $\mathrm{O}$ & $\mathrm{O}$ & $\mathrm{O}$ & & 4 \\
\hline & No. of product launches & $\mathrm{O}$ & & $\mathrm{O}$ & & $\mathrm{O}$ & $\mathrm{O}$ & & & & & & 4 \\
\hline & Revenue contribution ratio & & $\mathrm{O}$ & & & & & & & & & $\mathrm{O}$ & 2 \\
\hline & Return on equity & & & & & & & $\mathrm{O}$ & & & & & 1 \\
\hline & Equity growth rate & & & & & & & $\mathrm{O}$ & & & & & 1 \\
\hline & Patent registration rate & $\mathrm{O}$ & & & & & & & & & & & 1 \\
\hline & No. of patent citations & & & & $\mathrm{O}$ & & & & & & & & 1 \\
\hline & No. of patent claims & & & & $\mathrm{O}$ & & & & & & & & 1 \\
\hline & No. of innovative companies & & & & & & & & & & & $\mathrm{O}$ & 1 \\
\hline
\end{tabular}




\section{Methods}

\subsection{Research Model}

An input-based DEA model is used when the performing entity controls the inputs. However, in the technological innovation activities of SMEs, inputs such as R\&D personnel ratio, $R \& D$ headcount, $R \& D$ costs, and other innovation activity costs are difficult to control, making it difficult to apply the input-based model. Therefore, this study applied an output-based DEA model that maximizes outputs with the given inputs.

First, SMEs with technological innovation activities were selected based on the Korean Innovation Survey (KIS) data in 2016 and 2018, and the input and output variables were chosen.

Further, based on the methodological characteristics of the DEA, sufficient degrees of freedom should be considered when determining the number of DMU. When an excessively small number of DMUs are targeted, the efficient DMU ratio is relatively high. In general, it is recommended that the number of DMUs be at least three times the number of input and output variables [34]. Boussofiane et al. [62] argued that the number of DMUs should be more than the input variable $\times$ output variable. Dyson et al. [63] stated that it is desirable to exceed the input element $x$ the output element $\times 2$. However, the criteria for more than a few times mentioned in previous studies are not theoretically essential requirements, but empirical views that previous researchers have secured discrimination power.

In this study, four input variables and two output variables are used, and 185 DMUs, 10 times more than 18 DMUs, three times the total sum of the variables mentioned in previous studies, were secured to ensure reliability.

Next, DEA was used to measure TE, PTE, and SE (TE/PTE); and the average efficiency values derived from the analysis were classified into high- and low-efficiency groups to construct an efficient portfolio model. The characteristics of the high- and low-efficiency groups were evaluated, and the Wilcoxon-Mann-Whitney test was used to verify whether there were significant differences between the groups. Finally, a Tobit regression analysis was performed to investigate the factors affecting efficiency. Since the efficiency values in DEA were limited to a range between 0 and 1 , their distribution was different from the normal distribution of ordinary regression models, and the coefficient of regression had inconsistent estimates, requiring Tobit regression. When the OLS regression model is difficult to apply, Tobit regression analysis can be performed for regression analysis between dependent and independent variables with limited values [64]. Using Tobit analysis, if we analyze the relationship between the efficiency index measured in DEA as the dependent variable and the potential factors that are estimated to affect efficiency as the independent variable, we can determine whether a specific factor increases or decreases efficiency.

Finally, the statistics for each strategy of the significant influential factors derived through the Tobit regression analysis were examined to identify the strategic sub-factors that affected efficiency between groups. Figure 1 illustrates the research model used in this study.

\subsection{Data Collection and Characteristics}

The data were secured from the KIS conducted in 2016 and 2018, ensuring objectivity. The KIS was conducted by Gallup Korea and targeted South Korean manufacturing and service companies to investigate the technologically innovative performance of the companies between 2013 and 2017 (the investigation scope of 2016 KIS: 2013-2015, the investigation scope of 2018 KIS: 2015-2017). The "innovation" defined in the data refers to new or drastically improved products or service products, which are limited to those that affected the corporate operation performance, such as revenue, costs, quality, and efficiency after implementing the innovation [1]. According to the classification of industries, innovation is product innovation for the manufacturing industry and service product innovation for the service industry; the definitions of both are set forth below. 


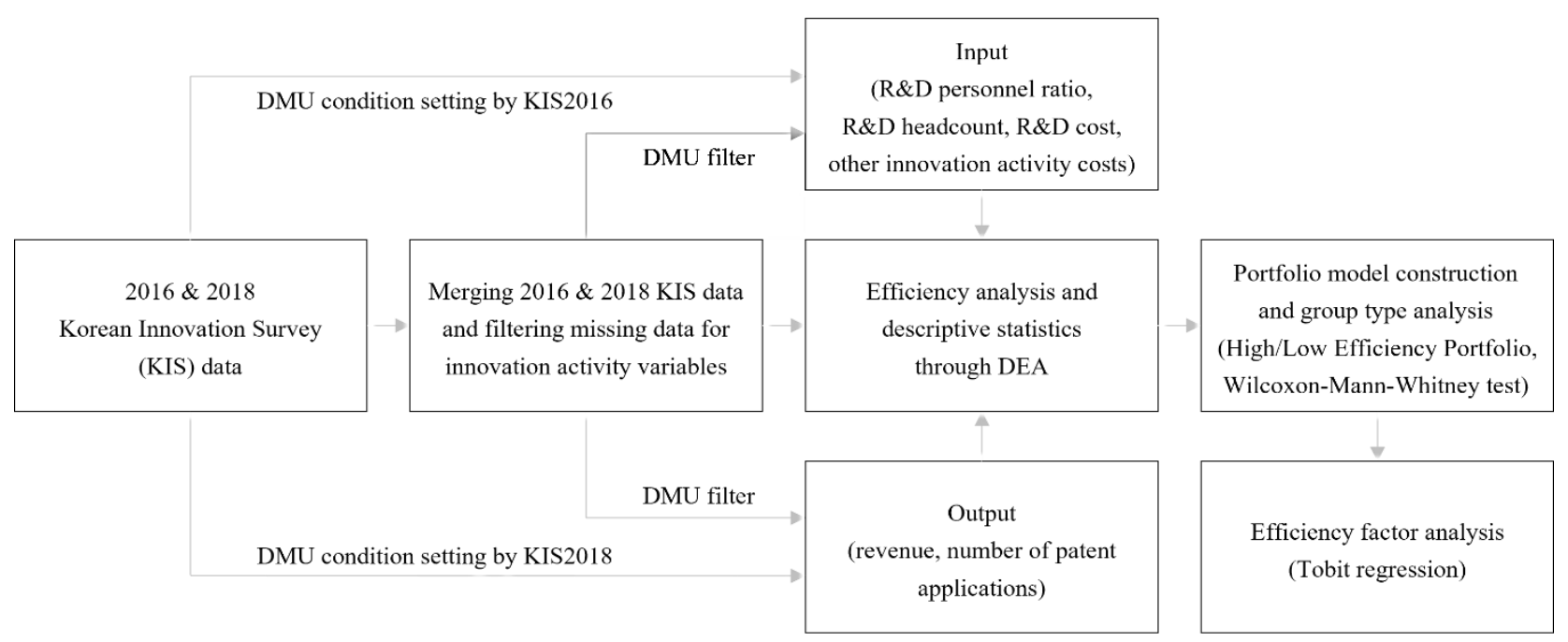

Efficiency comparison and influential factor analysis for South Koran SMEs in the manufacturing and service industries

Figure 1. Research framework.

In product innovation, a completely different product or significantly improved product is launched in the market, which affects a company's sales revenue. However, new models or design changes with similar technical performance or levels are not considered product innovations. In service product innovation, a new service and business model is developed, or an existing technology (know-how) is improved scientifically and systematically, thereby affecting the company's sales revenue.

The companies analyzed in this study are SMEs in the KIS database that incurs expenditures on innovation activities. Innovation activity expenditures include internal R\&D, external R\&D, machinery and equipment purchases, external knowledge purchases, and other activity costs. Furthermore, the input and output variables were selected considering that a time lag of one to two years occurs between the timing of a company's R\&D investment and performance outcome [65-67]. Based on this, 185 companies were selected with no missing data for the input variables, output variables, and other items required for the analysis.

In terms of company characteristics, $16.22 \%$ (30) of the companies were publicly listed companies, and $83.73 \%$ (155) were private companies, as shown in Table 3. Among them, 80 companies belonged to the service industry, of which $20.00 \%$ (16) were listed companies, and $80.00 \%$ (64) were non-listed companies. In the manufacturing industry, $13.33 \%$ (14) of 105 companies were listed companies, and $86.67 \%$ (91 companies) were non-listed companies.

Table 3. Company characteristics.

\begin{tabular}{|c|c|c|c|c|c|c|c|}
\hline \multirow{3}{*}{$\begin{array}{c}\text { Listed/ } \\
\text { Non-listed }\end{array}$} & \multirow[b]{2}{*}{ Listed } & \multicolumn{2}{|c|}{ Manufacturing Industry } & \multicolumn{2}{|c|}{ Service Industry } & \multicolumn{2}{|c|}{ Total } \\
\hline & & 14 & $13.33 \%$ & 16 & $20.00 \%$ & 30 & $16.22 \%$ \\
\hline & Non-listed & 91 & $86.67 \%$ & 64 & $80.00 \%$ & 155 & $83.78 \%$ \\
\hline & Fewer than 15 years & 17 & $16.19 \%$ & 12 & $15.00 \%$ & 29 & $15.68 \%$ \\
\hline \multirow[t]{3}{*}{ Company age } & $15-29$ years & 57 & $54.29 \%$ & 46 & $57.50 \%$ & 103 & $55.68 \%$ \\
\hline & 30 years or longer & 31 & $29.52 \%$ & 22 & $27.50 \%$ & 53 & $28.65 \%$ \\
\hline & Total & 105 & $56.76 \%$ & 80 & $43.24 \%$ & 185 & $100 \%$ \\
\hline
\end{tabular}


In terms of company age, $15 \%(29), 55 \%(103)$, and $28 \%(53)$ of the companies were less than 15 years, 15-29 years, and 30 years or older, respectively. By industry, 15.00\% (12), $57.50 \%(46)$, and $27.50 \%$ (22) of the companies in the service industry were less than 15 years, 15-29 years, and 30 years or older, respectively; $16.19 \%$ (17), 54.29\% (57), and 29.52\% (31) of the companies in the manufacturing industry were less than 15 years, 15-29 years, and 30 years or older, respectively. In other words, the distribution of the companies included in this study based on the founding year showed that most companies were 15 years or older, and the company age-based distribution was similar between the two industries.

\subsection{Variable Selection}

The DMUs were limited to SMEs that incurred innovation activity costs to satisfy the criteria in terms of homogeneity, a prerequisite for DEA. The characteristics of the companies must be reflected as much as possible while selecting realistically obtainable variables to derive efficiency properly through the DEA. Therefore, R\&D personnel ratio, R\&D personnel headcount, total R\&D costs, and other innovation costs were selected as input variables for the DEA model to compare the efficiency of the technological innovation activities between the manufacturing and service SMEs as well as to analyze the influencing factors. Based on previous studies, labor and costs are most frequently used as output variables in innovation efficiency studies, and they are important factors in creating innovative performance outcomes.

Not everyone within a company participates in technological innovation activities, and activity contribution levels vary by employee role. Therefore, this study was limited to R\&D personnel directly involved in innovation activities rather than all employees.

In the case of R\&D personnel, headcount is used as a major input factor in efficiency analysis $[8,25,57,60]$. This study used both $R \& D$ personnel indicators in the efficiency analysis since the proportion of R\&D personnel in the total headcount of a company is also an important input factor $[27,28]$.

The KIS also provides information on the total cost of innovation activities divided among five sub-category items (internal R\&D costs, external R\&D costs, machinery and equipment costs, external knowledge purchase costs and other activity costs). Therefore, this study combined internal and external R\&D costs to compose an R\&D cost indicator, generally used in studies on the efficiency of technological innovation activities. Moreover, the remaining machinery and equipment costs, external knowledge purchase costs, and other activity costs were combined into "other innovation activity costs" to investigate the efficiency of the costs of innovation activities other than R\&D for manufacturing and service companies.

The revenue and number of patent applications were used as the output variables. Durana, Zauskova, Vagner and Zadnanova [22], Liu, Hou, Zhan and Wang [25], Park, Kang, Shim and Ha [61], and Wang and Zhou [28] also used revenue as an output indicator of efficiency.

Furthermore, patents are one of the most powerful measures to protect the results of corporate technological innovation activities. Thus, this study uses the number of patent applications as a quantitative output variable. The number of patent applications is a major output indicator that has been examined in many past studies, such as those of Choi, Gwon, Song and Hwang [56], Lee, Kim and Choi [60], Liu, Hou, Zhan and Wang [25], Kim [58], Kim, Kim and Kim [59], Ren, Zhang and Yi [27], and Suh and Kim [8]. Table 4 summarizes the input and output variables used in DEA. 
Table 4. Selected input and output variables for DEA.

\begin{tabular}{|c|c|c|}
\hline Type & Variable & Measurement Method \\
\hline \multirow{3}{*}{ Input } & R\&D personnel ratio & $\begin{array}{l}\text { Percentage of R\&D personnel in total employees } \\
\text { (unit: \%, as of 2015) }\end{array}$ \\
\hline & R\&D headcount & $\begin{array}{l}\text { Number of R\&D personnel } \\
\text { (unit: persons, as of 2015) }\end{array}$ \\
\hline & Total R\&D costs & $\begin{array}{l}\text { Total internal and external R\&D costs } \\
\quad \text { (unit: } 1 \text { million won, as of 2015) }\end{array}$ \\
\hline \multirow{3}{*}{ Output } & Other innovation activity costs & $\begin{array}{l}\text { Total costs of innovation activities excluding internal and external R\&D } \\
\text { costs (unit: } 1 \text { million won, as of 2015) }\end{array}$ \\
\hline & Revenue & $\begin{array}{l}\text { Average revenue of } 2016 \text { and } 2017 \\
\text { (unit: } 1 \text { million won) }\end{array}$ \\
\hline & Number of patent applications & $\begin{array}{l}\text { Number of patent application cases } \\
\text { (unit: cases, the sum of application cases in 2015-2017) }\end{array}$ \\
\hline
\end{tabular}

\section{Results}

\subsection{Descriptive Statistics of Input and Output Variables}

Table 5 presents the descriptive statistics of the input and output variables. The input variables averages were $9 \%$ for the $R \& D$ personnel ratio, 12 employees for the R\&D headcount, 360 million won for the total R\&D costs, and 270 million won for other innovation activity costs. The output variables averages were 46.17 billion won for revenue and two for patent applications. The company with the highest R\&D personnel ratio was $50 \%$ of its total employees and largest R\&D headcount of 60 people. The largest amount of internal and external R\&D costs was a company that injected 2.41 billion won.

Table 5. Descriptive statistics of the data.

\begin{tabular}{cccccc}
\hline Input and Output Factors & Unit & Average & $\begin{array}{c}\text { Standard } \\
\text { Deviation }\end{array}$ & Max & Min \\
\hline R\&D personnel ratio & $\%$ & 9 & 9 & 50 & 0 \\
R\&D headcount & persons & 12 & 13 & 60 & 0 \\
Total R\&D costs & million won & 356 & 472 & 490 & 0 \\
Other innovation activity costs & million won & 272 & 53,124 & 427,571 & 1210 \\
Revenue & million won & 46,171 & 5 & 30 & 0 \\
Number of patent applications & cases & 2 & & & 0 \\
\hline
\end{tabular}

$\mathrm{DMU}=185$

Meanwhile, the company with the largest amount of other innovation activity expenditures (machinery and equipment costs, external knowledge purchase costs, and other activity costs), excluding internal and external R\&D costs, spent 4.27 billion won. The company with the largest revenue showed an average revenue of 427.6 billion won (based on 2016 and 2017), and the smallest revenue showed an average revenue of 1.2 billion won. The number of patent applications ranged from 0 to 30 .

Table 6 shows the results of the analysis of the correlations between the input and output variables. A positive correlation was found between most variables. Specifically, R\&D headcount and R\&D costs showed significant positive correlations with every input and output variable. Other innovation activity costs showed a positive correlation with every variable, except for the R\&D personnel ratio. The number of patent applications is positively correlated with every input and output variable, except for revenue. Despite nonsignificant positive correlations between some variables, these variables are still important for the efficiency analysis, indicating plausibility in the input and output results [31]. 
Table 6. Results of the correlation analysis.

\begin{tabular}{|c|c|c|c|c|c|c|}
\hline Variable & $\begin{array}{c}\text { R\&D } \\
\text { Personnel } \\
\text { Ratio }\end{array}$ & $\begin{array}{c}\text { R\&D } \\
\text { Headcount }\end{array}$ & $\begin{array}{c}\text { Total } \\
\text { R\&D Costs }\end{array}$ & $\begin{array}{c}\text { Other } \\
\text { Innovation } \\
\text { Activity Costs }\end{array}$ & Revenue & $\begin{array}{c}\text { No. of } \\
\text { Patent } \\
\text { Applications }\end{array}$ \\
\hline $\begin{array}{l}\text { R\&D } \\
\text { personnel ratio }\end{array}$ & 1.000 & & & & & \\
\hline $\begin{array}{c}\text { R\&D } \\
\text { headcount }\end{array}$ & $0.624^{* * *}$ & 1.000 & & & & \\
\hline $\begin{array}{c}\text { Total } \\
\text { R\&D costs }\end{array}$ & $0.337^{* * *}$ & $0.461^{* * *}$ & 1.000 & & & \\
\hline Other innovation activity costs & 0.091 & $0.206^{* *}$ & $0.238^{* *}$ & 1.000 & & \\
\hline Revenue & -0.127 & $0.201^{* *}$ & 0.130 & $0.146^{*}$ & 1.000 & \\
\hline No. of patent applications & $0.170 *$ & $0.301 * * *$ & $0.180 *$ & $0.218 * *$ & 0.088 & 1.000 \\
\hline
\end{tabular}

\subsection{Efficiency Analysis Using DEA}

As shown in Table 7, the TE based on the CCR model was 0.285 (28.5\%) on average, PTE based on the BCC model was 0.447 (44.7\%) on average, and SE was $0.627(62.7 \%)$ on average. Since SE was $18 \%$ higher than PTE, it was deduced that the main cause of the inefficiency was purely technical factors-inefficient operation-rather than unfavorable situations caused by the scale. The number of companies with an efficiency index of 1 was $13(7.0 \%)$ in the CCR model and $17(9.2 \%)$ in the BCC model. Meanwhile, in a relative comparison with companies showing maximum efficiency (efficiency $=1$ ), the number of companies showing $50 \%$ or higher efficiency with an efficiency index greater than or equal to 0.5 , and less than 1 was $29(15.7 \%)$ in the CCR model and $47(25.4 \%)$ in the BCC model. Conversely, the number of companies with an efficiency index of less than 0.5 , was $143(77.3 \%)$ in the CCR model and $121(65.4 \%)$ in the BCC model, indicating that $65-77 \%$ of the companies had relatively poor efficiency. The number of companies in which the combination of inputs and outputs achieved the maximum SE with a SE index of 1 was $27(14.6 \%)$.

Table 7. Summary of output-oriented DEA results.

\begin{tabular}{ccccc}
\hline Type & Average & Efficiency $=\mathbf{1}$ & $\mathbf{0 . 5} \leq$ Efficiency $<\mathbf{1}$ & Efficiency $<\mathbf{0 . 5}$ \\
\hline Technical Efficiency & & 13 & 29 & 143 \\
(CCR Model) & 0.285 & $7.03 \%$ & $15.67 \%$ & $77.30 \%$ \\
Pure Technical Efficiency & 0.447 & 17 & 47 & 121 \\
(BCC Model) & & $9.19 \%$ & $25.41 \%$ & $65.40 \%$ \\
Scale Efficiency & 0.627 & 27 & 85 & 73 \\
\end{tabular}

$\mathrm{DMU}=185$.

The efficiency was examined by dividing the manufacturing and service industries. Table 8 shows the changes in the descriptive statistics of the input and output variables investigated. The TE in the CCR model was $0.244(24.4 \%)$ for the manufacturing industry and $0.338(33.8 \%)$ for the service industry. The PTE in the BCC model was $0.343(34.3 \%)$ for the manufacturing industry and $0.582(58.2 \%)$ for the service industry. Hence, in both the CCR and BCC models, the service industry showed a higher efficiency. However, SE was $0.653(65.3 \%)$ in the manufacturing industry and $0.592(59.2 \%)$ in the service industry, indicating a relatively larger scale of inefficiency.

Furthermore, by examining the changes in the descriptive statistics of the input and output variables between the manufacturing and service industries, it was found that the values of every input variable were higher in the manufacturing industry than in the service industries. Conversely, the average revenue (output variable) was 43.5 billion won in the manufacturing industry and 49.6 billion won in the service industry, which is 
6.1 billion won higher. Therefore, labor and costs quantitatively showed that innovation activities were more efficient in the service industry than in the manufacturing industry. Moreover, the number of patent applications (output variable) was an average of 2.1 in the manufacturing industry, which was similar to the average of 2.0 in the service industry, confirming numerically that the service industry achieved a similar efficiency of innovation activities as the manufacturing industry with smaller inputs.

Table 8. Manufacturing and service industry efficiency indicators.

\begin{tabular}{cccc}
\hline & Type & $\begin{array}{c}\text { Manufacturing } \\
\text { Industry }\end{array}$ & Service Industry \\
\hline & DMU (quantity) & 105 & 80 \\
Efficiency Indicator & Technical efficiency (CCR model) & 0.244 & 0.338 \\
& Pure technical efficiency (BCC model) & 0.343 & 0.582 \\
Input & Scale efficiency & 0.653 & 0.592 \\
& R\&D personnel ratio (avg, \%) & 7.1 & 11.2 \\
Output & R\&D headcount (avg, persons) & 11.7 & 203.3 \\
& Total R\&D cost (avg, million won) & 471.7 & 271.8 \\
& Other innovation activity costs (avg, million won) & 273.0 & $49,626.1$ \\
& Revenue (avg, million won) & 2.0 & 2.0 \\
\hline
\end{tabular}

$$
\mathrm{DMU}=185 \text {. }
$$

\subsection{Comparison of Characteristics between Low- and High-Efficiency Groups}

Based on the average values of TE (CCR model) and PTE (BCC model), companies with an efficiency greater than or equal to the average were classified as high-efficiency companies; those with less than average efficiency were classified as low-efficiency companies. Next, they were classified into manufacturing and service industries to compose a matrix, as shown in Figure 2. The CCR model classified 32 manufacturing-high-efficiency companies, 73 manufacturing-low-efficiency companies, 35 service-high-efficiency companies, and 45 service-low-efficiency companies. Conversely, the BCC model classified 26 manufacturing-high-efficiency companies, 79 manufacturing-low-efficiency companies, 47 service-high-efficiency companies, and 33 service-low-efficiency companies. Subsequently, the efficiency differences between the high-efficiency and low-efficiency groups for the CCR and BCC models were compared. The differences between the groups were $52.6 \%$ and $50.7 \%$ in the manufacturing and service industries, respectively, based on the CCR model, and $67.3 \%$ and $75.8 \%$ in the manufacturing and service industries, respectively, based on the BCC model. This indicates a stark difference in efficiency between the highand low-efficiency groups.

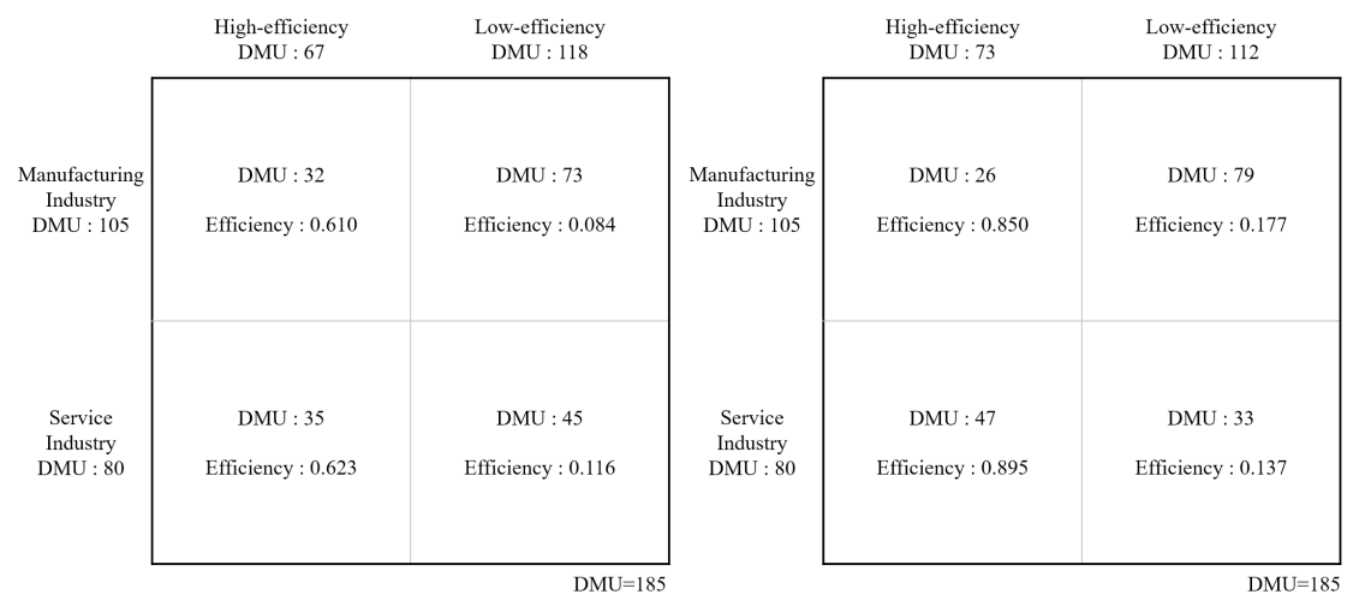

(a)

(b)

Figure 2. Efficiency matrix between high- and low-efficiency groups. (a) CCR model; (b) BCC model. 
Table 9 shows the results of the efficiency characteristics between the high- and lowefficiency groups by using the "listed/non-listed status" and "input" information examined previously in Section 3.2. Comparing the innovation efficiency between the non-listed and publicly listed company groups, both TE and PTE were higher in the non-listed company group (CCR: 0.300, BCC: 0.462), and the non-listed-service-high-efficiency group (CCR: 0.616, BCC: 0.954$)$ was the most efficient. The efficiency values of the listed company group (CCR: 0.206, BCC: 0.368) were relatively lower than those of the non-listed group, and most of the listed manufacturing and service companies belonged to the low-efficiency group, with overall efficiencies lower than the average.

When efficiency was compared between the group of companies established in 2000 or before and after 2000, both TE and PTE were higher in the latter group (CCR: 0.309, BCC: 0.486), indicating higher innovation efficiencies. Likewise, the manufacturing-highefficiency group also showed that the group of relatively young companies established after 2000 (CCR: 0.635, BCC: 0.751) had higher innovation efficiency in both TE and PTE. Conversely, in the service-high-efficiency group, the group of relatively young companies established after 2000 (CCR: 0.611, BCC: 0.509) showed lower efficiencies than those established in 2000 or before (CCR: 0.636, BCC: 0.541 ).

\subsection{Comparative Analysis between Groups}

The Wilcoxon-Mann-Whitney analysis was conducted before comparing the influential factors between the high- and low-efficiency groups of the manufacturing and service industries, to examine whether the efficiency components distributed in the comparison groups showed significant differences (Table 10).

When the DEA sample consists of several groups, comparing the effectiveness between groups is as important as the analysis of influencing factors. Efficiency values calculated in DEA are not statistically distributed but are calculated by a formula that follows specific conditions; therefore, general test methods cannot be used to compare efficiencies between groups. As a result, a nonparametric method is used to compare the efficiency between groups, of which the Wilcoxon-Mann-Whitney test is useful for comparing two independent groups [21,32].

Both the CCR and BCC models showed significant differences between the highand low-efficiency groups in the manufacturing industry and between the high- and lowefficiency groups in the service industry. Furthermore, the companies in the manufacturing and service industries in the high-efficiency group were compared with those in the lowefficiency group. The efficiency components also showed significant differences, confirming that there were differences between the efficiency of companies in the manufacturing and service industries, even within the same efficiency group level.

\subsection{Analysis of Influential Factors between Groups}

Tobit regression analysis was performed to identify factors that affect efficiency. The independent and dependent variables were set as follows. The factors that were believed to affect the efficiency of innovation activities were set as independent variables: the operation of an R\&D department (yes/no), external cooperation for technological innovation (yes/no), external funding for technological innovation (yes/no) and the implementation of organizational innovation (yes/no). The results of the CCR and BCC models were set as dependent variables. As shown in Table 11, both the CCR and BCC models showed a significant negative correlation with the operation of an R\&D department. This means that when a research center or a dedicated $R \& D$ team was in operation, the efficiency of innovation activities declined. Given that negative correlations also appeared similar in the service-low-efficiency group of the CCR model and the service-high-efficiency group of the BCC model, it was confirmed that inefficiency generally exists in operating a dedicated $R \& D$ department in the service industry. 
Table 9. Comparison of average efficiency by characteristic between high- and low-efficiency groups.

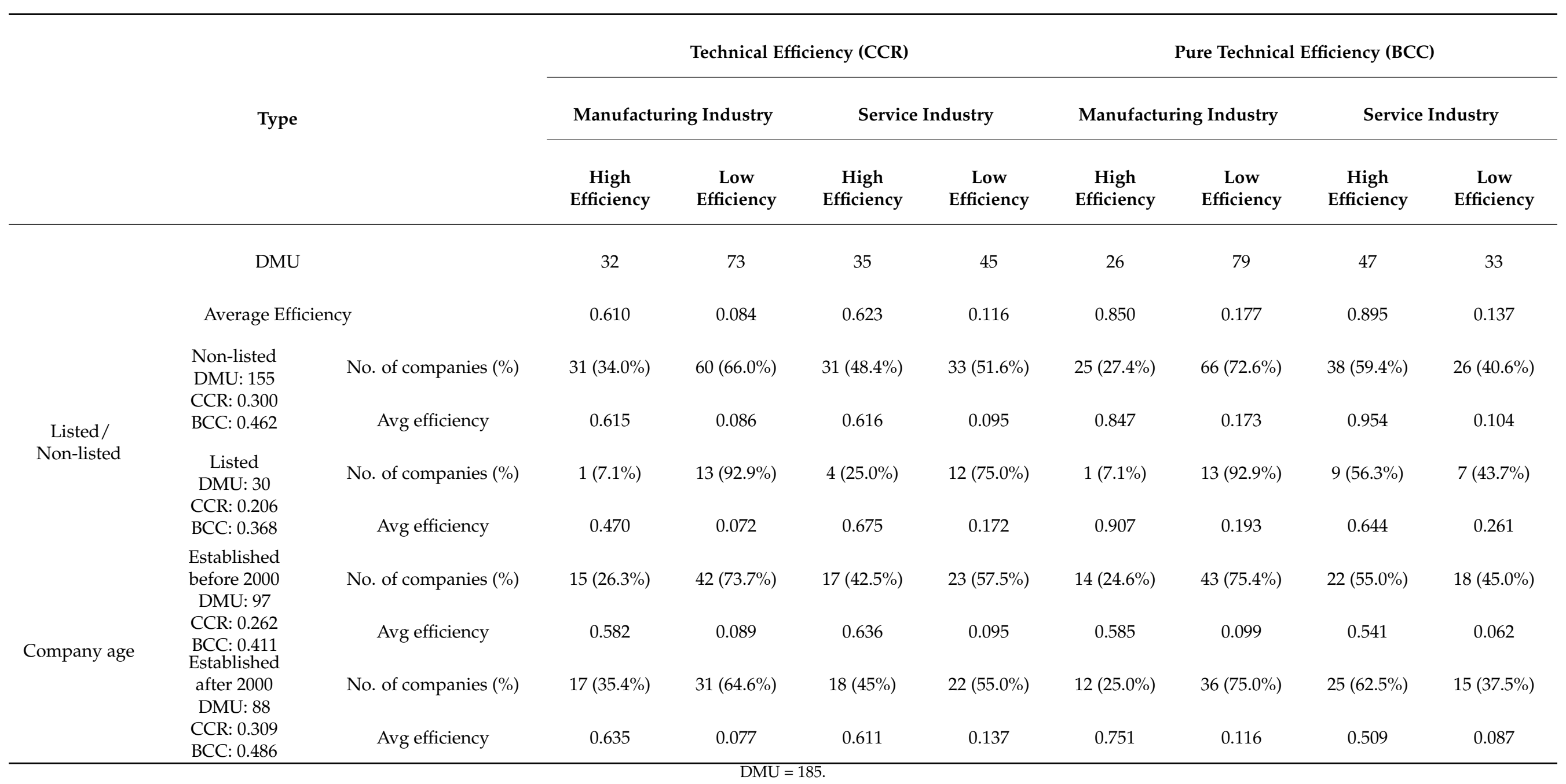


Table 10. Results of Wilcoxon-Mann-Whitney test.

\begin{tabular}{|c|c|c|c|c|c|c|c|}
\hline \multirow[b]{2}{*}{ Type } & \multirow[b]{2}{*}{ Comparison Group } & \multicolumn{3}{|c|}{ Technical Efficiency (CCR) } & \multicolumn{3}{|c|}{ Pure Technical Efficiency (BCC) } \\
\hline & & $\begin{array}{c}\text { Wilcoxon } \\
\text { Rank Sum } \\
\text { Test } \\
\text { Statistics }\end{array}$ & $\begin{array}{c}\text { z-Test } \\
\text { Statistics }\end{array}$ & $p$-Value & $\begin{array}{c}\text { Wilcoxon } \\
\text { Rank Sum } \\
\text { Test } \\
\text { Statistics }\end{array}$ & $\begin{array}{c}\text { z-Test } \\
\text { Statistics }\end{array}$ & $p$-Value \\
\hline 1 & $\begin{array}{l}\text { Manufacturing-high-efficiency } \\
\text { Manufacturing-low-efficiency }\end{array}$ & 1840.00 & -2.691 & $0.007^{* * *}$ & 351.00 & -4.457 & $0.001^{* * *}$ \\
\hline 2 & $\begin{array}{l}\text { Service-high-efficiency } \\
\text { Service-low-efficiency }\end{array}$ & 980.00 & -5.221 & $0.001^{* * *}$ & 1128.00 & -5.968 & $0.001^{* * *}$ \\
\hline 3 & $\begin{array}{l}\text { Manufacturing-high-efficiency } \\
\text { Service-high-efficiency }\end{array}$ & 390.00 & -3.730 & $0.001^{* * *}$ & 528.00 & -4.946 & $0.001^{* * *}$ \\
\hline 4 & $\begin{array}{l}\text { Manufacturing-low-efficiency } \\
\text { Service-low-efficiency }\end{array}$ & 1968.00 & -3.395 & $0.001^{* * *}$ & 3160.00 & -7.722 & $0.001^{* * *}$ \\
\hline
\end{tabular}

Significance level: ${ }^{* * *} 0.01$.

In the manufacturing-high-efficiency group, both TE and PTE were higher when the technological innovation fund was raised externally than when internal resources were used for innovation activities. This implies that the scale expansion of innovation through external fundraising is a major factor in the increase of efficiency in the high-efficiency manufacturing group.

Table 11. Analysis of influencing factors through Tobit regressions.

\begin{tabular}{|c|c|c|c|c|c|c|}
\hline & \multirow[b]{2}{*}{ Type } & \multirow[b]{2}{*}{ All } & \multicolumn{2}{|c|}{ Manufacturing Industry } & \multicolumn{2}{|c|}{ Service Industry } \\
\hline & & & $\begin{array}{c}\text { High- } \\
\text { Efficiency } \\
\text { Companies }\end{array}$ & $\begin{array}{c}\text { Low- } \\
\text { Efficiency } \\
\text { Companies }\end{array}$ & $\begin{array}{c}\text { High- } \\
\text { Efficiency } \\
\text { Companies }\end{array}$ & $\begin{array}{c}\text { Low- } \\
\text { Efficiency } \\
\text { Companies }\end{array}$ \\
\hline \multirow{5}{*}{$\begin{array}{l}\text { Technical } \\
\text { Efficiency } \\
\text { (CCR) }\end{array}$} & Intercept & $0.484^{* * *}$ & $0.591^{* * *}$ & 0.051 & $0.492 * * *$ & $0.217^{* * *}$ \\
\hline & $\begin{array}{l}\text { Operation of R\&D } \\
\text { department }(\mathrm{y} / \mathrm{n})\end{array}$ & $-0.277^{* * *}$ & -0.056 & 0.036 & 0.094 & $-0.136^{* * *}$ \\
\hline & $\begin{array}{c}\text { External cooperation for } \\
\text { technological innovation }(\mathrm{y} / \mathrm{n})\end{array}$ & -0.056 & $-0.208^{* *}$ & -0.007 & $0.365^{*}$ & -0.052 \\
\hline & $\begin{array}{l}\text { External funding for } \\
\text { technological innovation }(\mathrm{y} / \mathrm{n})\end{array}$ & 0.080 & $0.365^{* * *}$ & -0.012 & 0.086 & 0.071 \\
\hline & $\begin{array}{l}\text { Implementation of organizational } \\
\text { innovation }(\mathrm{y} / \mathrm{n})\end{array}$ & 0.015 & 0.087 & 0.002 & $0.142 *$ & 0.022 \\
\hline \multirow{7}{*}{$\begin{array}{c}\text { Pure } \\
\text { Technical } \\
\text { Efficiency } \\
\text { (BCC) }\end{array}$} & Log-likelihood & -17.917 & 6.451 & 95.330 & 4.471 & 58.352 \\
\hline & Intercept & $0.846^{* * *}$ & $0.824^{* * *}$ & 0.071 & $0.929^{* * *}$ & $0.095^{* * *}$ \\
\hline & $\begin{array}{l}\text { Operation of R\&D } \\
\text { department }(y / n)\end{array}$ & $-0.574^{* * *}$ & -0.076 & 0.079 & $-0.295^{* * *}$ & - \\
\hline & $\begin{array}{c}\text { External cooperation for } \\
\text { technological innovation }(\mathrm{y} / \mathrm{n})\end{array}$ & -0.087 & -0.055 & -0.004 & -0.026 & 0.014 \\
\hline & $\begin{array}{l}\text { External funding for } \\
\text { technological innovation }(\mathrm{y} / \mathrm{n})\end{array}$ & 0.119 & $0.202^{*}$ & 0.042 & 0.057 & -0.020 \\
\hline & $\begin{array}{l}\text { Implementation of organizational } \\
\text { innovation }(\mathrm{y} / \mathrm{n})\end{array}$ & 0.054 & 0.103 & 0.043 & 0.068 & $0.074^{* *}$ \\
\hline & Log-likelihood & -27.648 & 8.161 & 58.097 & 29.797 & 30.312 \\
\hline
\end{tabular}

Significance level: ${ }^{* * *} 0.01,{ }^{* *} 0.05,{ }^{*} 0.1$.

In the case of external cooperation for technological innovation, the service and manufacturing industries had the opposite effect. For the service-high-efficiency group in the CCR model, efficiency increased when companies had external cooperation for technological innovations. However, for the manufacturing-high-efficiency group in the CCR model, external cooperation for technological innovations resulted in a negative correlation, 
indicating a decrease in the efficiency of innovation activities. This demonstrates that the same influential factor can have opposite effects depending on the industry.

For the service industry, the service-high-efficiency group of the CCR model and the service-low-efficiency group of the BCC model showed a positive correlation, indicating an increase in the efficiency of technological innovation when organizational innovation was implemented. This means that organizational innovations such as changes in the performing work or those in work performing organizations, acted as an influential factor that increased the performance of technological innovations in the service industry.

\section{Conclusions}

This study comparatively analyzed the efficiency of SMEs' technological innovation activities in the manufacturing and service industries using the DEA method. Companies were divided into high- and low-efficiency groups based on average efficiency values, and the influential factors affecting the high and low efficiencies were analyzed. A DEA of output-based models, which maximized the output variables using the input variables related to the companies' technological innovation activities, was applied to measure efficiency. The CCR and BCC models were analyzed together and the SE was checked to identify the factors impacting efficiency.

In the efficiency analysis of 185 DMUs targeting SMEs, 13 (7.0\%) and 17 (9.2\%) companies had an efficiency index of 1 in the CCR and BCC models, respectively. Conversely, $143(77.3 \%)$ and $121(65.4 \%)$ companies had an efficiency index of less than 0.5 , in the CCR and BCC models, respectively, implying that most companies had relatively low efficiency, requiring efficiency improvement.

By classifying the manufacturing and service industries, both the CCR and BCC models showed that efficiency was higher in the service industry than in the manufacturing industry. However, SE was lower in the service industry than in the manufacturing industry, which meant that there was relative scale inefficiency in the service industry compared to the manufacturing industry. It seems that efficiency can be improved in the service industry through the quantitative expansion of input variables.

The companies were divided into high- and low-efficiency groups based on the average TE (CCR model) and average PTE (BCC model), which were then classified into manufacturing and service industries to construct a matrix. Subsequently, a Tobit regression analysis was conducted to analyze the influential factors impacting the efficiency difference between the high- and low-efficiency groups and between the service and manufacturing industries.

Based on the analysis, strategic implications were derived to contribute to the establishment of corporate technological innovation strategies. First, the inefficiency of a dedicated R\&D department is confirmed. In both the manufacturing and service industries, a significant negative correlation was found when a company operated an R\&D department. This indicates the presence of inefficiency in operating R\&D departments in the manufacturing and service industries.

The data for this study, the 2018 Korean Enterprise Innovation Survey, include data from a survey analysis conducted by company officials on factors that hinder the innovation activities of target companies. Among the factors hindering innovation under corporate capabilities, stakeholders answered the most importance as the "lack of information on technology and the market (23.2\%)," ranked the highest. Next were the "lack of excellent manpower" (15.3\%), "lack of good ideas" (13.7\%), and "lack of cooperation partners" (10.4\%) (STEPI, 2018). These survey results are relevant to the negative correlation between the operations of the R\&D department. It can be said that the company's efforts to supply the latest information and the government's support system are the most important tasks to be resolved. When such support is provided, the efficiency of the R\&D department can also be improved.

Second, the need for external fundraising in the manufacturing industry was confirmed. The high-efficiency manufacturing group showed higher efficiency when the 
technological innovation fund was raised externally than when internal resources were used for innovation activities. The average amount spent per company on technological innovation activities in the group that performed innovation activities using internal funds only was 570 million won, whereas that of the group that raised technological innovation funds externally was 1.19 billion won. This implies that higher revenue and patent performance can be achieved by increasing the scale of innovation activities through external funds.

Moreover, most sources of external funds for technological innovation are government subsidies or bank loans with government policies. This shows that direct and indirect financial support from government policies has a positive impact on SMEs' technological innovation. The SME R\&D funding support project in South Korea began in 1993 as an industry-academia-institute joint technology development project. In 1998, the Korea Small Business Innovation Research Program, an SME technological innovation support project, was introduced. In 2001, the SME Technology Innovation Promotion Law came into effect, further revitalizing the SME support project [68]. The annual R\&D budget of the SME Venture Department was 38.1 billion won in 1997, which increased approximately 28 times to 1.1 trillion won in 2019 [69]. The SMEs that benefited from such government support projects had higher survival rates and sales compared to companies that did not benefit from supporting projects. This confirms the positive effects of government funding seen in this study, which corroborates the results of government statistics $[14,70]$.

Third, organizational innovation performance in the service industry also affects technological innovation performance. A positive correlation was shown for the service industry, indicating an increase in technological innovation when organizational innovation was implemented. Organizational innovation activities, such as changes performing work functions or changes in the organization, increase the performance of technological innovation in the service industry.

For SMEs, where human and physical resources are limited, it is an ongoing challenge and goal to create high performance through the efficient input of resources. As mentioned before, it is necessary to continuously understand the influential factors that affect technological innovation activities, such as improving the work efficiency of the research department and introducing organizational innovation activities. Based on this, high-efficiency companies should expand their strengths by properly understanding the factors affecting their technological innovation activities. Low-efficiency companies should make continuous improvement efforts for the causes of low efficiency. Additionally, the government's SME support policy, which includes direct and indirect financial support, has different effects on the efficiency of technological innovation by industry. Thus, it is necessary to formulate a technological innovation policy that considers the characteristics of each industry.

Next, we consider the possibility of the application or utilization of this study to other countries or regions. As of 2018, service industry productivity by country did not exceed the OECD average in 27 out of 33 countries. In addition, as of 2014, the manufacturing value-added ratio of 20 major countries among the 30 OECD countries did not exceed the OECD average of $30 \%$. Under these circumstances, it is expected that this study will contribute to the empirical study of the growth stagnation of the service and manufacturing industries that the world is facing.

According to the results of the analysis of SMEs in 34 OECD countries by the Korea Economic Research Institute in 2019, the proportion of SMEs among all enterprises in OECD countries was an average of $99.81 \%$; similar to the data for Korea. In addition, as of 2011, major countries in the world, including Germany, Japan, and Canada, also had a similar structure to Korea, with manufacturing and service industries accounting for an average of $89.2 \%$ of the workforce. Of course, the results of this study cannot be used as direct indicators for other countries. However, this study can be used as an empirical example in a similar social structure and make a methodological contribution to innovation research in other countries. 
This study has several limitations. First, DEA is an analysis based on the relative efficiency. Therefore, regardless of whether the results indicate efficient or inefficient SMEs, DEA shows relative efficiency, not absolute efficiency. In other words, this does not mean that there is no potential improvement in the companies identified as efficient in the analysis. Second, although the input and output variables used in the DEA analysis were selected based on previous studies related to corporate technological innovation activities, researcher subjectivity was nonetheless reflected in that selection. Third, to ensure the homogeneity and accuracy of the DMUs in the KIS data, those with missing values in the data required for analysis were excluded from the study, thereby reducing the number of DMUs. Therefore, there are some limitations in applying the results of this study to the innovation activities of all SMEs in South Korea. Furthermore, it is necessary to find additional input and output variables by investigating qualitative and quantitative variables that can reflect the efficiency of technological innovation activities more accurately. Despite these limitations, the results of this study are significant. It evaluates the efficiency of innovation activities of small and medium-sized manufacturing and service companies in South Korea and suggests specific criteria and rationales for improving it.

Author Contributions: Conceptualization: C.H.I. and K.T.C.; methodology: C.H.I. and K.T.C.; software: C.H.I.; validation, C.H.I. and K.T.C.; formal analysis, C.H.I. and K.T.C.; investigation, C.H.I. and K.T.C.; resources, C.H.I. and K.T.C.; data curation, C.H.I. and K.T.C.; writing-original draft preparation, C.H.I.; writing-review and editing, C.H.I. and K.T.C.; visualization, C.H.I.; supervision, K.T.C. All authors have read and agreed to the published version of the manuscript.

Funding: This research received no external funding.

Institutional Review Board Statement: Not applicable.

Informed Consent Statement: Not applicable.

Conflicts of Interest: The authors declare no conflict of interest.

\section{References}

1. OECD. Oslo Manual Guidelines for Collecting, Reporting and Using Data on Innovation; OECD: Paris, France, 2018 ; Volume 4.

2. Daemmrich, A. Invention, Innovation Systems, and the Fourth Industrial Revolution. Technol. Innov. 2017, 18, 257-265. [CrossRef]

3. Mao, C.; Koide, R.; Brem, A.; Akenji, L. Technology foresight for social good: Social implications of technological innovation by 2050 from a Global Expert Survey. Technol. Forecast. Soc. Chang. 2020, 153, 119914. [CrossRef]

4. Yoon, S.J.; Seo, J.H. Competence of Fourth Industrial Revolution Corporations on management Performance. Asia Pac. J. Samall Bus. 2021, 43, 51-83. [CrossRef]

5. KISDI. Change Image and Policy Suggestion in the Era of the 4th Industrial Revolution; KISDI: Deoksan-Myeon, Korea, 2016; Volume 16, pp. 1-38.

6. Schwab, K. The Fourth Industrial Revolution; Currency: Redfern, Australia, 2017.

7. Stock, G.N.; Greis, N.P.; Fischer, W.A. Firm size and dynamic technological innovation. Technovation 2002, 22, 537-549. [CrossRef]

8. Suh, Y.Y.; Kim, M.S. A comparative study on efficiency of technologically innovative activities between manufacturing and service industries using DEA. Ie Interfaces 2011, 24, 330-340. [CrossRef]

9. Bong, K.H.; Kim, S.; Park, J. A Study on the Determinants of Innovation Investment in Small and Medium-sized Enterprises Using Multinomial Logit Model. J. Korea Technol. Innov. Soc. 2020, 23, 140-161. [CrossRef]

10. Somohano-Rodríguez, F.M.; Madrid-Guijarro, A.; López-Fernández, J.M. Does Industry 4.0 Really Matter for SME Innovation? Available online: https:/ / www.tandfonline.com/doi/full/10.1080/00472778.2020.1780728 (accessed on 28 August 2020).

11. KIET. The influence and Challenges of the Fourth Industrial Revolution on Korean Major Industries; KIET: Amsterdam, The Netherlands, 2017; Volume 845, pp. 1-571.

12. Woo, J.H.; Kim, Y.J. An Analysis of the Hampering Factors of Innovation: Focusing on SMEs in Korean Manufacturing Industry. J. Korea Acad. -Ind. Coop. Soc. 2018, 19, 115-126. [CrossRef]

13. MSS. Scope of Small and Medium-Sized Enterprises; MSS Ministry of SMEs and Startups: Sejong-si, Korea, 2018.

14. Statistics Korea. 2019 Business Demography Statistics Result; Statistics Korea: Daejeon, Korea, 2020; pp. 1-72.

15. Maduekwe, V.C.; Oke, S.A. Novel Taguchi scheme-based DEMATEL methods and DEMATEL method for the principal performance indicators of maintenance in a food processing industry. Int. J. Intell. Comput. Cybern. 2021, 14, 363-397. [CrossRef]

16. ECOS. GDP and GNI by Economic Activity; ECOS Korea Economic Statistics System: Daejeon, Korea, 2020.

17. Gadrey, J.; Gallouj, F.; Weinstein, O. New modes of innovation: How services benefit industry. Int. J. Serv. Ind. Manag. 1995, 6, 4-16. [CrossRef]

18. Pavitt, K. Sectoral patterns of technical change: Towards a taxonomy and a theory. Res. Policy 1984, 13, 343-373. [CrossRef] 
19. Tether, B.S. Do Services Innovate (Differently)? Insights from the European Innobarometer Survey. Ind. Innov. 2005, 12, 153-184. [CrossRef]

20. Krajewski, L.J.; Ritzman, L.P. Operations Management: Strategy and Analysis, 5th ed.; Addison-Wesley: Melbourne, Australia, 1998.

21. Lee, H.; Park, Y.; Choi, H. Comparative evaluation of performance of national R\&D programs with heterogeneous objectives: A DEA approach. Eur. J. Oper. Res. 2009, 196, 847-855. [CrossRef]

22. Durana, P.; Zauskova, A.; Vagner, L.; Zadnanova, S. Earnings drivers of Slovak manufacturers: Efficiency assessment of innovation management. Appl. Sci. 2020, 10, 4251. [CrossRef]

23. Lee, S.H.; Lee, C.G.; Jung, D.W.; Moon, J.B. A study on the analysis of managerial efficiency and development of the Materials \& Components enterprises by using the Data Envelopment Analysis. J. Korea Manag. Eng. Soc. 2010, 15, 101-127.

24. Lee, S.Y. Efficiency measurement of public ent using DEA (Data Envelopment Analysis). Korean Public Manag. Rev. 2010, 24, 51-71. [CrossRef]

25. Liu, L.; Hou, Y.; Zhan, X.; Wang, Z. Innovation Efficiency of High-Tech SMEs Listed in China: Its Measurement and Antecedents. Discret. Dyn. Nat. Soc. 2020. [CrossRef]

26. Kim, J.K.; Kang, D.Y. Management Efficiency of Introduction Company of ERP System using DEA. J. Korea Contents Assoc. 2008, 8, 147-157. [CrossRef]

27. Ren, D.; Zhang, X.; Yi, J. Empirical Analysis on SME's Innovative Efficiency-A Case of SMEs in Guangdong Cluster of Materials Industry. In Proceedings of the 2010 International Conference on E-Business and E-Government, Washington, DC, USA, 7-9 May 2010; pp. 1120-1123.

28. Wang, Y.Y.; Zhou, Y. The Empirical Analysis of Technological Innovation Efficiency of Small and Medium-sized High-tech Enterprises in Xi'an High-tech Zone based on DEA. Adv. Mater. Res. 2015, 1065, 2495-2499. [CrossRef]

29. Yoon, M.K.; Kim, J.K. The Efficiency Analysis of Korea Stock Market Listed Top-200 Manufacturing Firms: Using the DEA Technic. Korea Corp. Manag. Assoc. 2006, 13, 79-97.

30. Charnes, A.; Cooper, W.W.; Lewin, A.Y.; Morey, R.C.; Rousseau, J. Sensitivity and stability analysis in DEA. Ann. Oper. Res. 1984, 2, 139-156. [CrossRef]

31. Park, M.H. Development of DEA efficiency and Malmquist productivity analysis system. Product. Rev. 2008, 22, 241-265.

32. Park, S.J.; Kim, K.H.; Jeong, S.K. The study on the analysis of efficiency of governmental R\&D programs regarding to the S\&T outcomes. J. Korea Technol. Innov. Soc. 2011, 14, 205-222.

33. Charnes, A.; Cooper, W.W.; Rhodes, E. Measuring the efficiency of decision making units. Eur. J. Oper. Res. 1978, 2, 429-444. [CrossRef]

34. Banker, R.D.; Charnes, A.; Cooper, W.W. Some models for estimating technical and scale inefficiencies in data envelopment analysis. Manag. Sci. 1984, 30, 1078-1092. [CrossRef]

35. Byrnes, P.; Färe, R.; Grosskopf, S. Measuring productive efficiency: An application to Illinois strip mines. Manag. Sci. 1984, 30, 671-681. [CrossRef]

36. Jahanshahloo, G.R.; Hosseinzadeh, F.; Shoja, N.; Sanei, M.; Tohidi, G. Sensitivity and stability analysis in DEA. Appl. Math. Comput. 2005, 169, 897-904. [CrossRef]

37. Bian, Y. Efficiency evaluation with undesirable factors based on DEA. In Proceedings of the 2008 4th International Conference on Wireless Communications, Networking and Mobile Computing, Dalian, China, 12-14 October 2008; pp. 1-5. [CrossRef]

38. Elsayed, A.; Khalil, N.S. Evaluate and Analysis Efficiency of Safaga Port Using DEA-CCR, BCC and SBM Models-Comparison with DP World Sokhna. Iop Conf. Ser. Mater. Sci. Eng. 2017, 245, 42033. [CrossRef]

39. Graubard, B.I.; Korn, E.L. Choice of column scores for testing independence in ordered 2 x K contingency tables. Biometrics 1987, 43, 471-476. [CrossRef]

40. Li, P.; Chen, H. Evaluation of Green Building Suppliers Based on IVPLTS-CBR Decision-Making Method. Available online: https: / / doi.org/10.1108/IJICC-06-2021-0118 (accessed on 2 September 2021).

41. Bogetoft, P.; Otto, L. Benchmarking with Dea, Sfa, and R; Springer Science \& Business Media: Berlin/Heidelberg, Germany, 2010; Volume 157.

42. Park, J.-M.; Lee, J.-M. How Do Firms' Innovation Behaviors Affect their Outputs in Korea? J. Korea Contents Assoc. 2011, 11, 339-350. [CrossRef]

43. Kang, S.; Park, S. A Relationship between Innovation Capability and Performance: Differences in Firm Development Stages. Asia-Pac. J. Bus. Ventur. Entrep. 2018, 13, 91-100. [CrossRef]

44. Bae, Y.I. Impact of R\&D expenditures on SMEs' employment: The moderating effect of Government R\&D funding. Asia-Pac. J. Bus. Ventur. Entrep. 2015, 10, 75-83. [CrossRef]

45. Sohn, D.; Lee, J.; Kim, Y. The effects of government support and regulation on SMEs technology innovation. J. Digit. Converg. 2017, 15, 117-125. [CrossRef]

46. Park, W.; Park, H.-Y.; Yeom, M.-B. The Effect on Technology Innovation Performance of Private-Public R\&D Cooperation of ICT SMEs: Focused on Collaboration with Government-funded Research Institutes. Asia-Pac. J. Bus. Ventur. Entrep. 2017, 12, 139-150.

47. Kang, S.-M. Analysis for Impact of Individual Cooperation Activity on Small and Medium sized Firms' Innovation Performance in Daegu: The Moderating Effect of Technological Capability. J. Korea Contents Assoc. 2021, 21, 404-413. [CrossRef] 
48. Yang, Y.; Xu, K.; Kang, Y. A study on financing efficiency of high-tech small and medium-sized enterprises in Beijing. In Proceedings of the 2009 International Conference on Management Science and Engineering, Moscow, Russia, 14-16 September 2009; pp. 1843-1847.

49. Buyukkeklik, A.; Dumlu, H.; Evci, S. Measuring the efficiency of turkish SMEs: A data envelopment analysis approach. Int. J. Econ. Financ. 2016, 8, 190-200. [CrossRef]

50. Lang, X. Study on Financing Efficiency of Listed Technology SMEs Based on DEA Method. Adv. Soc. Sci. Educ. Humanit. Res. 2020, 435, 450-455. [CrossRef]

51. Kim, Y.; Yoo, H.; Song, G. A Study on Operational Efficiency Measurement Using DEA in Small and Medium Companies Utilizing the ERP System: Focused on the Automobile Parts Industries. J. Korean Prod. Oper. Manag. Soc. 2008, 19, 155-179. [CrossRef]

52. Halkos, G.E.; Tzeremes, N.G. The effect of foreign ownership on SMEs performance: An efficiency analysis perspective. J. Product. Anal. 2010, 34, 167-180. [CrossRef]

53. Ha, S.Y.; Lee, G.H.; Kim, B.S. Strategies for manufacturing servitization of Korean smes: By using data envelopment analysis. J. Appl. Bus. Res. 2016, 32, 635-646. [CrossRef]

54. Charoenrat, T.; Harvie, C. The performance of Thai manufacturing SMEs: Data envelopment analysis (DEA) approach. Glob. Bus. Rev. 2017, 18, 1178-1198. [CrossRef]

55. Ahn, E.J.; Kim, S.; Park, S.M.; Kim, C.B. An Analysis on Operational Efficiency of Korean SMEs in Communication and Broadcasting Equipment Manufacturing Industry Using DEA Models. Korean Corp. Manag. Rev. 2020, 27, 87-108. [CrossRef]

56. Choi, J.I.; Gwon, S.H.; Song, S.H.; Hwang, S.W. A Study on Analyzing Innovation Efficiency in Service Sector of Korea. IE Interfaces 2009, 22, 336-346.

57. Guede-Cid, R.; Rodas-Alfaya, L.; Leguey-Galán, S.; Cid-Cid, A.I. Innovation Efficiency in the Spanish Service Sectors, and Open Innovation. J. Open Innov. Technol. Mark. Complex. 2021, 7, 62. [CrossRef]

58. Kim, E. Comparison of Innovation Efficiency of Pre-IPO and Post-IPO in Korea: Case of Pharmaceutical Industry. J. Technol. Innov. 2016, 24, 143-167. [CrossRef]

59. Kim, H.; Kim, J.; Kim, S.K. Measuring the efficiency of technology innovation of the Global Green Car Companies by ANP/DEA Model. J. Technol. Innov. 2012, 20, 255-285.

60. Lee, J.; Kim, C.; Choi, G. The effect of external R\&D on the innovation ef-ficiency: An empirical study of manufacturing industries in Korea. J. Soc. Korea Ind. Syst. Eng. 2016, 39, 125-136. [CrossRef]

61. Park, H.J.; Kang, Y.J.; Shim, W.J.; Ha, J.S. A Study on the Analysis of Management Efficiency of the Korean Robotics Industry Using DEA-SBM: Focused on a Technology Innovation Factor. Ind. Innov. Res. 2017, 33, 25-48. [CrossRef]

62. Boussofiane, A.; Dyson, R.G.; Thanassoulis, E. Applied data envelopment analysis. Eur. J. Oper. Res. 1991, 52, 1-15. [CrossRef]

63. Dyson, R.G.; Allen, R.; Camanho, A.S.; Podinovski, V.V.; Sarrico, C.S.; Shale, E.A. Pitfalls and protocols in DEA. Eur. J. Oper. Res. 2001, 132, 245-259. [CrossRef]

64. Park, H.G. The Efficiency Determinants to Port Cargo Equipment on Container Terminals to DEA \& Tobit Model. J. Korea Port. Econ. Assoc. 2010, 26, 1-17.

65. Kim, S.G.; Yeon, R.M. Effectiveness of R\&D investment on enterprise outcome. Korean J. Account. Res. 2007, 12, 1-31.

66. Lee, H.j.; Baek, C.; Lee, J.d. Analysis on Time Lag Effect of Firm's R\&D Investment. J. Technol. Innov. 2014, 22, 1-22. [CrossRef]

67. Pakes, A.; Schankerman, M. 4. The Rate of Obsolescence of Patents, Research Gestation Lags, and the Private Rate of Return to Research Resources; University of Chicago Press: Chicago, IL, USA, 2007. [CrossRef]

68. KISTEP. How Will the Government Design the SME RED Strategy? KISTEP (Korea Institute of Science \& Technology Evaluation and Planning): Eumseong-gun, Korea, 2019; Volume 2019-16.

69. KISTEP. Government Research and Development Budget Analysis of the FY 2019; KISTEP (Korea Institute of Science \& Technology Evaluation and Planning): Eumseong-gun, Korea, 2019; Volume 2019-02.

70. KISED. 2017 Startup Support. Company History E Performance Survey; KISED (Korea Institute of Startup and Entrepreneurship Development): Sejong-si, Korea, 2017. 